\title{
Article
}

\section{The effects of three quarter and full length foot orthoses on knee mechanics in healthy subjects and patellofemoral pain patients when walking and descending stairs}

Burston, J, Richards, James and Selfe, James

Available at http://clok.uclan.ac.uk/22308/

Burston, J, Richards, James ORCID: 0000-0002-4004-3115 and Selfe, James (2018) The effects of three quarter and full length foot orthoses on knee mechanics in healthy subjects and patellofemoral pain patients when walking and descending stairs. Gait \& Posture, 62 . pp. 518-522. ISSN 0966-6362

It is advisable to refer to the publisher's version if you intend to cite from the work. http://dx.doi.org/10.1016/j.gaitpost.2018.04.018

For more information about UCLan's research in this area go to http://www.uclan.ac.uk/researchgroups/ and search for <name of research Group>.

For information about Research generally at UCLan please go to http://www.uclan.ac.uk/research/

All outputs in CLoK are protected by Intellectual Property Rights law, including Copyright law. Copyright, IPR and Moral Rights for the works on this site are retained by the individual authors and/or other copyright owners. Terms and conditions for use of this material are defined in the policies page. 


\section{Accepted Manuscript}

Title: The effects of three quarter and full length foot orthoses on knee mechanics in healthy subjects and patellofemoral pain patients when walking and descending stairs

Authors: J. Burston, J. Richards, J. Selfe

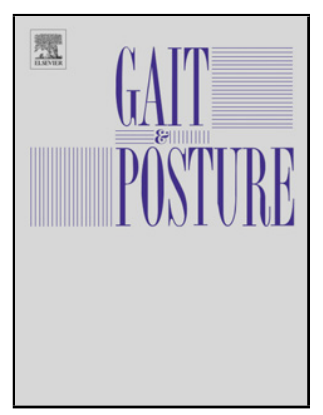

PII:

S0966-6362(18)30378-3

DOI: https://doi.org/10.1016/j.gaitpost.2018.04.018

Reference: GAIPOS 6051

To appear in:

Gait \& Posture

Received date:

$18-5-2017$

Revised date:

5-4-2018

Accepted date:

$13-4-2018$

Please cite this article as: Burston J, Richards J, Selfe J.The effects of three quarter and full length foot orthoses on knee mechanics in healthy subjects and patellofemoral pain patients when walking and descending stairs.Gait and Posture https://doi.org/10.1016/j.gaitpost.2018.04.018

This is a PDF file of an unedited manuscript that has been accepted for publication. As a service to our customers we are providing this early version of the manuscript. The manuscript will undergo copyediting, typesetting, and review of the resulting proof before it is published in its final form. Please note that during the production process errors may be discovered which could affect the content, and all legal disclaimers that apply to the journal pertain. 


\title{
The effects of three quarter and full length foot orthoses on knee mechanics in healthy subjects and patellofemoral pain patients when walking and descending stairs
}

\author{
J Burston ${ }^{\mathrm{a}, \mathrm{b}}$, J Richards ${ }^{\mathrm{b}}$, J Selfe ${ }^{\mathrm{c}}$

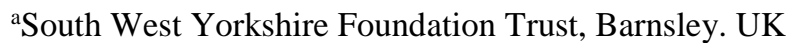 \\ ${ }^{\mathrm{b}}$ Allied Health Research unit, University of Central Lancashire, Preston. UK \\ ${ }^{\mathrm{c}}$ Department of Health Professions, Manchester Metropolitan University. UK
}

Highlights

Important differences in knee mechanics exist between the PFP and healthy group.

Foot orthoses normalise the coronal plane knee moment in PFP patients.

Changes in foot orthotic prescription impact on foot and knee mechanics.

\begin{abstract}
Background: An increased load of the patellofemoral joint is often attributed to foot function in patients with patellofemoral pain. Foot orthoses are commonly prescribed for this condition; however the mechanisms by which they work are poorly understood. The aim of this study was to investigate the kinematics and kinetics of the knee between patellofemoral pain patients and a group of healthy subjects when using a standardised foot orthosis prescription during walking and step descent. Method: Fifteen healthy subjects and fifteen patients diagnosed with PFP with a foot posture index greater than 6 , had foot orthoses moulded to their feet. They were asked to walk at a self-selected pace and complete a $20 \mathrm{~cm}$ step descent using customised orthoses with $3 / 4$ and full length wedges. Kinematic and Kinetic data were collected and modelled using Calibrated Anatomical System Technique.

Results: Significant differences were seen in both the kinematics and kinetics between the healthy group and the PFP patients at the knee. A significant reduction in the knee coronal plane moment was found during the forward continuum phase of step descent when wearing the foot orthoses; this was attributed to a change in the ground reaction force as there were no changes reported in the kinematics of the knee with the orthoses.

Conclusions: This study identified potentially clinically important differences in the knee mechanics between the PFP patients and the healthy group during walking and step descent. The foot orthoses reduced the coronal plane knee moment in the PFP patients to a value similar to that of the healthy subjects with no intervention.
\end{abstract}

Keywords: foot orthoses; knee mechanics; healthy subjects; patellofemoral pain patients; walking; descending stairs

\section{Introduction}

Patellofemoral pain (PFP) is one of the most common lower limb disorders seen in musculoskeletal clinics [1,2,3]. Consensus statements published from three International Patellofemoral Pain Research Retreats (IPFPRR) propose subgroups based on biomechanical risk factors described by anatomical location relative to the knee: Proximal, Local and Distal which referred to the lower leg and ankle. More recently Selfe et al. [4] identified 3 distinct 
patellofemoral pain subgroups, one of which was 'weak and pronated' defined by strength measurement of the quadriceps and hip abductors and a foot posture index (FPI) score over 6.

Currently there is no consensus about what is the best management for PFP, and a wide range of treatments have been suggested including foot orthoses, patellar taping, knee supports and physiotherapy[5]. Pitman and Jack [6] suggested that foot orthoses could be used as a first line treatment in PFP patients. While Gross and Foxworth [7] noted that the experimental evidence for using foot orthoses to combat PFP is "theoretical and circumstantial", however despite the variable results in the changes in mechanics with orthoses they concluded that PFP patients with pronated feet may benefit from the use of foot orthoses.

Barton et al. [12 ] explored the clinical responses when wearing foot orthoses were in 60 people with PFP. Significant improvements were seen after 12 weeks of use using the anterior knee pain scale and number of pain free step downs and single leg raises when wearing prefabricated foot orthoses. Further work on the clinical response was conducted by Collins et al. [8] who performed a randomised control trial on 179 participants with patellofemoral pain. They found that the prefabricated orthoses improved the subjects' pain scores in the short term compared to flat insoles but found no long-term benefit when combined with physiotherapy.

Powers [9] stated that orthoses were being provided without considering underlying biomechanics, therefore using orthoses to treat PFP is a "trial and error treatment", suggesting the link between patellofemoral joint function and foot pronation is tenuous. Powers et al. [10] later reported that there is some evidence to suggest foot orthoses are useful in the treatment of PFP, however a greater understanding is needed on how foot function affects the patellofemoral joint. Boldt et al. [11] suggested that medially wedged orthoses reduce retro-patellar stress by limiting calcaneal eversion and tibial rotation, however results across studies are inconsistent. In addition, little has been published different designs of orthoses which can include $3 / 4$ length and full-length foot orthoses, and whether these can have an influence on joint stability during different tasks is unknown.

Selfe et al. $[13,14]$ highlighted that a dynamic "challenge" for the knee is needed to explore the effect of different treatment options in people with PFP. Step descent was proposed due to the increased eccentric control it requires over a greater knee range of motion in closed chain. Selfe, et al. used a $20 \mathrm{~cm}$ step descent task where participants were asked to descend as slowly 
as possible with no intervention, tape and a soft brace. They reported reductions in the range of coronal and transverse plane angles and moments, this was purported as an improvement in knee joint control. Selfe, et al. [13] concluded that coronal and torsional kinematics and kinetics must not be excluded when investigating step descent. However, to the authors knowledge, there have been no studies conducted exploring the biomechanical effects of foot orthoses during step descent.

Despite the amount of work that has been conducted on different interventions in patients with PFP, little data exists exploring the differences in knee kinematics between patients with PFP and healthy subjects, and whether interventions such as foot orthoses can have a differential effect. Therefore, the purpose of this study was to investigate if differences exist in the kinematics and kinetics of the knee between a group PFP patients and a group of healthy subjects and to identify if they reacted similarly to standardised foot orthoses prescriptions during walking and step descent at self-selected speeds.

The hypotheses were a) PFP patients have different knee biomechanics during walking and step descent to healthy subjects, b) foot orthoses change knee biomechanics during walking and step descent, c) PFP and healthy subjects react in a similar way to the different foot orthoses prescriptions.

\section{Method}

\section{Participants}

Fifteen healthy subjects and fifteen patients with a diagnosis of PFP were recruited from a University staff and student population. The healthy group consisted of 7 males and 8 females mean age 30.1 (s.d. 10.0), with a mean FPI score of 6.3 (+4 to +9 ). PFP patients consisted of 8 men and 7 women, mean age 28.6 years (s.d. 5.8), mean FPI score of 7.9 (+6 to +10$)$ [15], and suffering with pain around the patella with visual analogue pain score of at least 3 on a regular basis following sport or descending stairs. Inclusion criteria included; pronated feet, no history of knee surgery or back pain. Three subjects did not meet the inclusion criteria; one with a supinated foot posture and two with back pain.

Procedures

Five repetitions of self-selected speed level walking and a $20 \mathrm{~cm}$ step descent task were performed under three conditions: no orthoses, $3 / 4$ length foot orthoses and full-length foot 
orthoses. The rationale for this was that full-length orthoses may provide greater stability during step descent over the more frequently provided $3 / 4$ length orthoses. The healthy subjects descended with their preferred limb, while the PFP group descended on their most affected limb. The orthoses were customised to each subject by using a correctly sized pair of Slimflex ${ }^{\mathrm{TM}}$ insoles. These were heated and moulded to the longitudinal arch profile of each subject (Figure 1), and supported with low density EVA (shore 30) with no posting (Figure 2). A standard $5^{\circ}$ medially wedged EVA post of either $3 / 4$ length or full-length was placed under the moulded orthoses in the subjects own training shoes.

Kinetic data were collected at $200 \mathrm{~Hz}$ using four AMTI force plates. A series of three steps of heights $20 \mathrm{~cm}, 40 \mathrm{~cm}$ and $20 \mathrm{~cm}$ were placed on the force plates for the step-descent task. Kinematic data were collected using a ten camera infra-red Oqus motion analysis system (Qualisys medical AB, Sweden) at $100 \mathrm{~Hz}$. Passive retro-reflective markers were placed on the lower limbs. To reduce measurement error reflective markers were positioned by a single experienced researcher with the participant in a relaxed anatomical standing position and all data were collected during a single visit [16]. Anatomical markers were positioned on the anterior superior iliac spine, posterior superior iliac spine, greater trochanter, medial and lateral femoral epicondyle, medial and lateral malleoli and over medial and lateral aspects of $1^{\text {st }}$ and $5^{\text {th }}$ metatarsal respectively. Additionally, clusters of non-collinear markers were attached to the shank and thigh using the Calibrated Anatomical System Technique [17]. Markers were also placed over forefoot, mid-foot and rearfoot aspects of the shoes. Raw kinematic and kinetic data were exported to Visual3D (C-Motion Inc., USA). Kinematic and kinetic data were filtered using fourth order Butterworth filters with cut off frequencies of 6 and $25 \mathrm{~Hz}$, respectively. Anatomical frames were defined by landmarks positioned at the medial and lateral borders of the joint, from these right handed segment co-ordinate systems were defined and the hip joint centre positions were calculated based on pelvic depth and width using the regression equations developed by Bell et al.[18]. Knee kinematics were calculated based on the cardan sequence of XYZ, equivalent to the joint co-ordinate system [19] and knee kinematic and kinetic data were quantified for stance phase during walking and from toe off and initial contact of the contralateral side for step descent.

\section{Data Analysis}

Mixed Methods ANOVAs were performed to explore differences between the healthy group and PFP patients, the 3 conditions and to determine if any interactions exist between the group 
and condition. Further post hoc pairwise comparisons were performed using the least significant difference method to compare no orthoses with the orthotic conditions. The dependant variables for gait were: walking speed; maximum, minimum and range of knee joint angles and moments in the sagittal, coronal and transverse planes during stance phase. Stance phase was divided into early stance (double support), mid-stance (single limb support) and late stance (double support), which were defined by heel strike and toe off timings. The dependant variables for the step descent task included; the knee joint angles and moments as above, which were determined during the forward continuum phase and lowering phase [20], and single limb stance time. The range of moment in the coronal and transverse planes was considered of particular interest as this has previously been used to determine the level of stability during step descent $[13,14]$.

\section{Results}

For walking the mixed methods ANOVAs showed no interactions seen between groups and condition ( $\mathrm{p}=0.56$ to 0.99$)$. Significant differences were seen in the knee kinematics and kinetics between the healthy group and PFP patients during stance phase; however these generally showed low effect sizes. No significant differences were seen between conditions. The PFP patients extended the knee further than the healthy subjects, and demonstrated a difference in knee adduction and abduction angles, with a trend towards the PFP patients having a larger coronal plane range of motion. Both maximum external rotation and transverse plane range of motion of the knee were significantly higher in the PFP patients during early stance. In addition, patients showed a reduced range of coronal plane moment during early stance, which demonstrated the largest effect size during walking, and greater knee flexion moment during late stance, Table 1.

As with walking, step descent showed no interactions between group and condition in any of the kinematic or kinetic variables $(p=0.44$ to 0.98$)$. Significant differences were seen between groups for both kinematics and kinetics during strep descent, which generally had larger effect sizes than the results during walking. For the kinematics, the PFP patients had a significantly longer single limb stance time, greater maximum knee flexion angle, greater range of flexion, greater coronal and transverse plane range of motion, and lower maximum adduction/abduction angles than the healthy group. No significant differences in the kinematics of the knee between the conditions in any plane, Table 2. 
Significant differences were seen in the knee moments between groups. The PFP patients had a greater peak knee flexion moment during the lowering phase, and greater knee adduction moment during the forward continuum phase, with greater coronal plane moment range during both phases. In the transverse plane, the rotational moment range was greater in the PFP patients during the forward continuum phase but there were no differences during the lowering phase, Table 2.

The range of moment in the coronal plane during the forward continuum phase during step descent was the only parameter to show a significant difference between conditions $(p=0.032)$. No interaction was seen indicating this effect occurred in both groups. A further pairwise analysis showed that both orthotic $3 / 4$ and full-length prescriptions significantly reduced the coronal moment range during the forward continuum phase $(\mathrm{p}=0.019, \mathrm{p}=0.028)$ respectively, however no differences were seen between the orthoses, Table 3.

\section{Discussion}

We hypothesised PFP patients have different knee biomechanics during walking and step descent to healthy subjects. The PFP group did not flex their knees as much as the healthy group during loading response and toe off and tended to extend more during mid-stance. This may be a compensation strategy to aid knee stability and reduce patellofemoral compression. However, range of motion the coronal and transverse planes during early stance were significantly greater in the patients, which may relate more to the aetiology and joint instability proposed by Selfe et al. [14]. Both the maximum abduction and adduction moments were marginally greater in the healthy group during early stance phase, this resulted in the coronal moment range being significantly smaller in the PFP patients, although it is questionable whether this is a clinically important difference. During late stance phase the healthy group demonstrated a trend towards having a greater adduction moment which was in contrast to the findings of Paoloni et al. [21], and may be due to differences in foot type, however foot type was not reported by Paoloni, et al.

This study found greater differences between the PFP patients and healthy subjects than has been previously reported during walking $[21,24,25,26]$. Differences were seen in all three planes with the PFP group showing greater knee excursions than the healthy group. This would 
question the statement that walking is not "strenuous" enough to induce compensation mechanisms [27,28]. Although, only the step descent task showed significant differences between the groups, which included in single limb support time, knee kinematics and moments in all planes. This is in contrast to pervious work by Salsich et al. and Brechter et al. [23] who found no differences between symptomatic and non-symptomatic groups.

Although there are many references to sagittal plane motion of the knee during step descent, fewer studies report coronal plane motion. Yu et al. [16] compared level walking with stair ascent and descent. They reported that all three tasks were undertaken with the knee in a varus position, but peak angle was greatest during stair ascent and descent. This was in contrast to the present results were walking demonstrated a small increase of $1^{\circ}$ over the step descent trials. In this current study, we found that coronal plane excursion was significantly larger in the PFP patients, which has been reported as a measure of reduced control [13].

It is difficult to compare the rotational moments of the knee, as little data has been reported in the literature, despite the internal/external rotational movement of the tibia on the femur having clinically important implications to the tracking of the patella. Selfe et al. [14] investigated the coronal and transverse kinematics and kinetics. They suggested that reducing both the ranges of motion and the range of moments could help with the treatment of patellofemoral pain.

During walking and step descent the maximum flexion moments were greater in the later stages of both tasks in the PFP patients compared to the healthy group which has been linked to greater patellofemoral compression [29,30]. In addition, the maximum adduction moment and coronal moment range were greater in the PFP patients during the forward continuum phase of step descent indicating greater instability. However, the PFP patients demonstrated a reduced knee adduction moment and coronal moment range during early stance phase when walking, suggesting a possible coronal plane compensation strategy to increase the stability of the knee.

We hypothesised that foot orthoses would change knee biomechanics during walking and stepdown tasks. However, no differences were seen between the orthoses and the control during walking, which appears to be consistent with Boldt et al. [11] who reported that the orthoses had little effect on knee or hip joint mechanics albeit during running. Boldt et al. also found that a PFP group tended to react to orthoses in a similar manner to a control group. However, this does not support the clinically held belief that medially wedging a foot will have the effect 
of increasing the adduction moment, and appears to contradict the findings of Gross and Foxworth [7] who reviewed the effects of orthoses and suggested that there was limitation of tibial internal rotation.

The authors could find no other data in the literature that investigated the effect of foot orthoses on knee kinematics during step descent. The foot orthoses used in this study did not affect knee kinematics during step descent in either the PFP or the healthy group. However, the range of moment in the coronal plane at the knee was significantly reduced by both orthoses, which could be linked to the foot being less everted and therefore more stable. This effect was seen in both the PFP and healthy groups with no significant interactions between group and orthoses, indicating no differential effect on the patients. Further studies are required to investigate individually prescribed orthoses to patients with different foot types and the effect on the hip control, which may be able disguising subtle effects suggested by Payne et al. [31]. Further work, similar to the study conducted by Bellchamber and van Den Bogart. [32], could explore the power flow to determine if hip or foot mechanics has the greatest influence during step descent, and whether the adduction seen in the patients in this study could be a dominant compensatory mechanism to unload the lateral facet of the patella during step descent.

Limitations of this study include; the exact matching of foot postures between groups, which could in part be responsible for some of the differences between groups, although the two groups only had 1.5 point difference in FPI score. The foot positioning during step descent was not controlled which could influence the results, however this study took the pragmatic view that controlling for this may result in individuals changing their strategy, therefore masking any differences between the groups.

It should be noted that by not controlling speed of walking or the step descent time could have introduced some changes due to velocity, however it was felt important not to put any restrictions on the subjects to allow them to function in their usual manner. During walking no significant differences were seen in velocity, however patients took significantly longer when performing the step descent task.

Footwear type was standardised to training shoes, however participants wore their own shoes and variations in design could have influenced the findings. No consideration was given to individuals being biomechanical responders/non-responders to the foot orthoses within the 
different groups, this is an important consideration for future work and has been recently highlighted by Kim et al. [33].

\section{Conclusion}

This study identified potentially important differences in the knee mechanics between the PFP patients with a FPI $>6$ and the healthy group during walking and step descent. The foot orthoses reduced the coronal plane knee moment during the forward continuum phase during step descent. Further investigations are necessary to establish whether targeted intervention of custom fabricated orthoses in PFP patients with FPI $>6$ improves patient outcomes.

Competing interests: There are no conflicts of interest of competing interests in this work. 


\section{References}

[1] Vincenzino, B., Collins,N., Crossley, K., Beller, E., Darnell, R., McPoil, T., Foot Orthoses and Physiotherapy in the Treatment of Patellofemoral Pain Syndrome: A Randomised Clinical Trial. BMC Musculoskeletal Disorders 2008; 9, 27 doi:10.1186/14712474-9-27

[2] Willson, J.D., Davis, I.S., Lower Extremity Mechanics of Females with and without Patellofemoral Pain Across Activities with Progressively Greater Task Demands. Clinical Biomech. 2008; 23. 203-211.

[3] Barton, C.J., Levinger, P., Crossley, K.M., Webster, K.E., Menz, H.B., Relationships between the foot posture index and foot kinematics during gait in individuals with and without patellofemoral pain syndrome. J.Foot Ankle Res. 2011; 4.(10).

http//:www.jfootankleres.com/content/4/10

[4] Selfe J, Dey P, Callaghan M, Witvrouw E, Richards J, Sutton C, Stokes M, Martin D, Dixon J, Hogarth R, Baltzopoulos V, Ritchie E, Arden N, Turner D, Masters R, Polman R, Janssen J. Are there three main subgroups within the patellofemoral population? A detailed characterisation study of 127 patients to help develop targeted intervension (TIPPS). Br J Sports Med 2016; doi:10.1136/bjsports-2015-094792.

[5] Hossain M, Alexander P, Burls A, Jobanputra P. Foot orthoses for patellofemoral pain in adults (Protocol). Cochrane Database of Systematic Reviews 2010; 3, CD008402.

[6] Pitman, D., Jack, D. A Clinical Investigation to Determine the Effectiveness of Biomechanical Foot Orthoses as Initial Treatment for Patellofemoral Pain Syndrome. JPO. 2000; 12(4):110-116.

[7] Gross, M.T, Foxworth, J.L. The Role of Foot Orthoses as an Intervension for Patellofemoral Pain. J Orthop Sports Phys Ther. 2003; 33(11):661-670.

[8] Collins N, Crossley K, Beller E, Darnell R, McPoil T, Vicenzino B. Foot Orthoses and Physiotherapy in the Treatment of Patellofemoral Pain Syndrome: Randomised Clinical Trial. BMJ 2008; 337:a1735.

[9] Powers C. Patellofemoral pain: Is there a role for orthoses. American Academy Phys Med and Rehab. 2010; 2(8). 771-776.

[10] Powers CM, Bolgia L, Callaghan M, Collins N, Sheehan F. Patellofemoral pain: proximal, distal, and local factors. $2^{\text {nd }}$ international research retreat 2011, Ghent Belgium. J Orthop. Sports Phys Ther. 2012; 42(6): A1-A20.

[11] Boldt AR, Wilson JD, Barrios JA, Kernozek TW. Effects of medially wedged foot orthoses on knee and hip joint running mechanics in females with and without patellofemoral pain syndrome. J Applied Biomech. 2013; 29:68-77.

[12] Barton CJ, Levinger P, Webster KE, Menz HB. Walking Kinematics in individuals with patellofemoral Pain syndrome: A case control study. Gait and Posture. 2011; 33:286-29. 
[13] Selfe J, Richards J, Thewlis D, Kilmurray S. The Biomechanics of Step Descent under Different Treatment Modalities used in Patellofemoral Pain. Gait and Posture. 2008; doi:10.1016/j.gaitpost.2007.03.017.

[14] Selfe J, Thewlis D, Hill S, Whitaker J, Sutton C, Richards J. A clinical study of the biomechanics of step descent using different treatment modalities for patellofemoral pain. Gait and Posture. 2011; 34:92-96.

[15] Redmond AC, Crane YZ, Menz HB. Normative values for the Foot Posture Index. J Foot Ankle Res. 2008; 1:6.

[16] Yu B, Kienbacher T, Growney ES, Johnson ME, An KN. Reproducibility of the kinematics and kinetics of the lower extremity during normal stair- climbing. J Ortho Research, 1997; 15(3):348-352.

[17] Cappozzo A, Catani F, Leardini A, Benedeti MG, Della CU. Position and orientation in space of bones during movement: Anatomical frame definition and determination. Clinical Biomechanics1995; 10:171-178.

[18] Bell AL, Pedersen DR, Brand RA. A comparison of the accuracy of several hip center location prediction methods. J Biomech. 1990; 23(6):617-621.

[19] Grood E, Suntay W. A joint cocorinate system for the clinical description of threedimensional motions: application to the knee. Trans ASME 1983; 105:136-144.

[20] McFadyen BJ, Winter DA. An Integrated Biomechanical Analysis of Normal Stair Ascent and Descent. J Biomech. 1988; 21(9): 733-744.

[21] Paoloni M, Mangone M, Fratocchi G, Murgia M, Saraceni VM, Santilli V. Kinematic and Kinetic Features of Normal Level Walking in Patellofemoral Pain Syndrome: More than a Sagittal Plane Alteration. J.Biomech. 2010; doi:10.1016/j.jbiomech.2010.02.013.

[22] Salsich GB, Brechter JH, Powers CM. Lower extremity kinetics during stair ambulation in patients with and without patellofemoral pain. Clinical Biomech. 2001; 16: 906-912.

[23] Brechter JH, Powers CM. Patellofemoral Joint Stress during Stair Ascent and Descent in Persons with and without Patellofemoral Pain. Gait and Posture. 2002; 16:115-123.

[24] Powers CM, Heino JG, Rao S, Perry J. The Influence of Patellofemoral Pain on Lower Limb Loading During Gait. Clinical Biomech. 1999; 14:722-728.

[25] Noehren B, Pohl MB, Sanchez Z, Cunningham T, Latterman C. Proximal and distal kinematics in female runners with patellofemoral pain. Clinical Biomech. 2011; doi: 10.10.16/j.clinbiomech.2011.10.005.

[26] Leitch J, Reilly K, Stebbins J, Zavatsky A. Joint kinematics in runners with patellofemoral pain syndrome. Gait and Posture. 2012; 36(1):S18. 
[27] Crossley KM, Cowan SM, Bennell KL, McConnell J. Knee Flexion during Stair Ambulation is altered in Individuals with Patellofemoral Pain. J Orthop Res. 2004; 22:267274.

[28] Willson JD, Davis IS. Lower Extremity Mechanics of Females with and without Patellofemoral Pain Across Activities with Progressively Greater Task Demands. Clinical Biomech. 2008; 23:203-211.

[29] Andriacchi TP, Andersson GBJ, Fermier RW, Stern D, Galante JO. A study of lowerlimb mechanics during stair-climbing. JBJS. 1980; 62-A, (5): 749-757.

[30] Farrokhi S, Keyak JH, Powers CM. Individuals with patellofemoral pain exhibit greater patellofemoral joint stress: a finite element analysis study. Osteoarthritis and Cartilage.2011; 19: 287-294.

[31] Payne C, Oates M, Mitchel A. The Response of the Foot to Prefabricated Orthoses of Different Arch Heights. Aus J Pod Med. 2002; 36(1):7-12.

[32] Bellchamber TL, Van Den Bogart AJ. Contributions of Proximal and Distal Moments to Axial Tibial Rotation During Walking and Running. J Biomech. 2000; 33:1397-1403.

[33] Kim Y, Richards J, Lidtke RH, Trede R. Characteristics of clinical measurements between biomechanical responders and non-responders to a shoe designed for knee osteoarthritis. Gait \& Posture. 2018; 59:23-27.

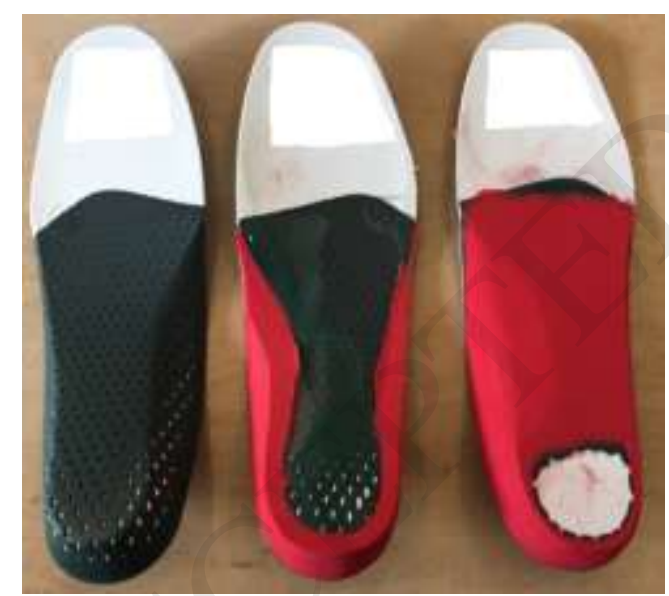

Fig. 1 Stages of insoles being supported with shore 30 EVA

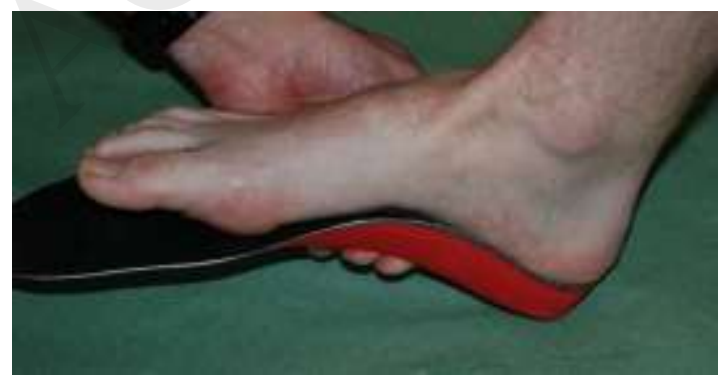

Fig. 2 customised insole fitted to longitudinal arch of each subject 
Table 1. Mean (sd) Knee Kinematics and Moments during Walking for the Healthy group and PFP patients under the 3 conditions.

\begin{tabular}{|c|c|c|c|c|c|c|c|c|}
\hline \multirow[b]{2}{*}{ Knee Kinematics Walking } & \multicolumn{3}{|c|}{ Healthy } & \multicolumn{3}{|c|}{ PFP Patients } & \multirow{2}{*}{$\begin{array}{l}\text { Healthy v PFP } \\
\text { p-values } \\
\text { effect size }\left(p \eta^{2}\right)\end{array}$} & \multirow{2}{*}{$\begin{array}{l}\text { CI of the } \\
\text { Differences }\end{array}$} \\
\hline & Shoe & $3 / 4$ & FL & Shoe & $3 / 4$ & FL & & \\
\hline Flexion at Heel Strike & $8.6(4.2)$ & $8.5(4.4)$ & $8.6(6.5)$ & $7.2(6.5)$ & $6.6(6.7)$ & $6.9(7.0)$ & $\mathrm{p}=0.054(0.021)$ & -0.03 to 3.33 \\
\hline Max Flexion ES* & $26.0(4.9)$ & $26.9(4.7)$ & $26.2(4.9)$ & $24.6(6.4)$ & $24.6(6.6)$ & $24.8(6.4)$ & $\mathbf{p}=\mathbf{0 . 0 4 6}(0.020)$ & 0.03 to 3.38 \\
\hline Max Extension during MS * & $9.3(3.7)$ & $9.4(4.3)$ & $9.4(3.9)$ & $6.4(5.8)$ & $6.6(5.7)$ & $6.3(6.2)$ & $\mathbf{p}<\mathbf{0 . 0 0 1}(0.080)$ & 1.48 to 4.45 \\
\hline Max Flexion LS * & $49.9(4.6)$ & $48.6(5.9)$ & $49.1(6.0)$ & $47.1(6.3)$ & $46.9(6.0)$ & $47.3(6.5)$ & $\mathbf{p}=\mathbf{0 . 0 2 0}(0.030)$ & 0.33 to 3.81 \\
\hline Coronal Plane ROM * & $5.7(2.6)$ & $5.5(2.8)$ & $5.8(2.6)$ & $7.2(3.7)$ & $7.3(3.9)$ & $7.2(3.8)$ & $\mathbf{p}=\mathbf{0 . 0 0 2}(0.050)$ & -2.51 to -0.58 \\
\hline Transverse plane ROM ES* & $11.5(3.7)$ & $10.9(3.8)$ & $11.2(3.7)$ & $13.5(3.4)$ & $13.6(3.3)$ & $13.4(3.8)$ & $\mathbf{p}<\mathbf{0 . 0 0 1}(0.090)$ & -3.32 to -1.19 \\
\hline Walking Speed & $1.53(0.13)$ & $1.52(0.14)$ & $1.52(0.14)$ & $1.49(0.14)$ & $1.48(0.15)$ & $1.46(0.18)$ & $\mathrm{p}=0.118(0.030)$ & -0.11 to 0.01 \\
\hline \multicolumn{9}{|l|}{ Knee Moments Walking } \\
\hline Max Flexion Moment ES & $0.89(0.23)$ & $0.89(0.24)$ & $0.86(0.25)$ & $0.87(0.28)$ & $0.86(0.28)$ & $0.87(0.25)$ & $\mathrm{p}=0.656(0.001)$ & -0.06 to 0.09 \\
\hline Max Extension Moment & $-0.22(0.15)$ & $-0.17(0.14)$ & $-0.20(0.14)$ & $-0.20(0.13)$ & $-0.14(0.12)$ & $-0.19(0.14)$ & $\mathrm{p}=0.306(0.006)$ & -0.06 to 0.02 \\
\hline Max Flexion Moment LS * & $0.23(0.09)$ & $0.22(0.09)$ & $0.22(0.08)$ & $0.26(0.09)$ & $0.26(0.10)$ & $0.25(0.10)$ & $\mathbf{p}=\mathbf{0 . 0 5 0}(0.022)$ & -0.06 to 0.00 \\
\hline Coronal Moment Range ES * & $0.54(0.12)$ & $0.55(0.11)$ & $0.57(0.12)$ & $0.46(0.12)$ & $0.49(0.12)$ & $0.49(0.12)$ & $\mathbf{p}<\mathbf{0 . 0 0 1}(0.100)$ & 0.04 to 0.11 \\
\hline Transverse Moment Range & $0.23(0.07)$ & $0.22(0.06)$ & $0.22(0.07)$ & $0.21(0.04)$ & $0.22(0.04)$ & $0.22(0.04)$ & $\mathrm{p}=0.475(0.003)$ & -0.01 to 0.02 \\
\hline
\end{tabular}

* Significant difference between Groups, $\uparrow$ significant difference between Orthoses, $\$$ significant interaction between Group and Orthoses (ES - Early Stance, MS - Mid-stance, LS - Late Stance) 
Table 2. Mean (sd) Knee Kinematics and Moments during Step Descent for the Healthy group and PFP patients under the 3 conditions

\begin{tabular}{|c|c|c|c|c|c|c|c|c|}
\hline \multirow[b]{2}{*}{ Knee Kinematics Step Descent (deg) } & \multicolumn{3}{|c|}{ Healthy } & \multicolumn{3}{|c|}{ PFP Patients } & \multirow{2}{*}{$\begin{array}{c}\text { Healthy v PFP } \\
\text { p-value, } \\
\text { effect size }\left(\mathrm{p \eta}^{2}\right)\end{array}$} & \multirow{2}{*}{$\begin{array}{l}\text { CI of the } \\
\text { Difference }\end{array}$} \\
\hline & Shoe & $3 / 4$ & FL & Shoe & $3 / 4$ & FL & & \\
\hline Max Flexion $*$ & $71.8(7.4)$ & $71.4(6.9)$ & $72.2(7.3)$ & $76.8(9.2)$ & $76.8(8.8)$ & $76.1(9.6)$ & $\mathbf{p}=\mathbf{0 . 0 0 8}(0.080)$ & -8.2 to -1 . \\
\hline Max Adduction* & $-0.1(3.1)$ & $-0.1(3.0)$ & $0.4(3.0)$ & $-3.5(3.7)$ & $-3.3(3.7)$ & $-2.8(3.6)$ & $\mathbf{p}<\mathbf{0 . 0 0 1}(0.210)$ & 1.8 to 4.7 \\
\hline Max Abduction * & $3.8(3.2)$ & $3.5(3.3)$ & $3.8(3.2)$ & $1.8(3.7)$ & $1.7(3.8)$ & $2.3(3.5)$ & $\mathbf{p}=\mathbf{0 . 0 1 7}(0.066)$ & 0.3 to 3.2 \\
\hline Coronal Plane ROM * & $3.9(1.6)$ & $3.6(1.5)$ & $3.4(1.8)$ & $5.3(2.8)$ & $5.0(2.6)$ & $5.1(2.5)$ & $\mathbf{p}=\mathbf{0 . 0 0 2}(0.113)$ & -2.4 to -0 . \\
\hline Transverse Range FC * & $1.9(1.1)$ & $2.4(1.2)$ & $2.2(0.9)$ & $3.0(1.0)$ & $2.9(1.2)$ & $3.1(1.2)$ & $\mathbf{p}<\mathbf{0 . 0 0 1}(0.140)$ & -2.7 to 1 . \\
\hline Transverse Range LP & $3.9(2.0)$ & $3.7(1.7)$ & $4.1(1.9)$ & $3.8(1.7)$ & $3.9(2.6)$ & $3.9(2.6)$ & $\mathrm{p}=0.94(0.001)$ & -0.9 to 0. \\
\hline Single Limb Stance time (s) & $0.60(0.08)$ & $0.59(0.07)$ & $0.61(0.08)$ & $0.66(0.07)$ & $0.67(0.07)$ & $0.68(0.07)$ & $\mathbf{p}<\mathbf{0 . 0 0 1}(0.21)$ & 0.04 to 0 . \\
\hline \multicolumn{9}{|l|}{ Knee Moments Step Descent (Nm/kg) } \\
\hline Max Flexion Moment FC & $0.37(0.23)$ & $0.38(0.22)$ & $0.35(0.23)$ & $0.35(0.24)$ & $0.33(0.21)$ & $0.32(0.23)$ & $\mathrm{p}=0.470(0.006)$ & -0.06 to 0 . \\
\hline Flexion Moment Range FC & $0.25(0.14)$ & $0.21(0.12)$ & $0.22(0,11)$ & $0.24(0.11)$ & $0.21(0.11)$ & $0.21(0.07)$ & $\mathrm{p}=0.741(0.001)$ & -0.04 to 0 \\
\hline Max Flexion Moment LP $*$ & $1.36(0.23)$ & $1.44(0.27)$ & $1.40(0.25)$ & $1.54(0.18)$ & $1.57(0.20)$ & $1.50(0.21)$ & $\mathbf{p}=\mathbf{0 . 0 0 5}(0.092)$ & -0.23 to -0 . \\
\hline Max Adduction Moment FC * & $0.55(0.10)$ & $0.53(0.11)$ & $0.55(0.10)$ & $0.61(0.10)$ & $0.60(0.10)$ & $0.61(0.11)$ & $\mathbf{p}=\mathbf{0 . 0 0 2}(0.105)$ & -0.11 to -0 . \\
\hline Coronal Moment Range FC $* \dagger$ & $0.30(0.08)$ & $0.26(0.08)$ & $0.25(0.08)$ & $0.35(0.06)$ & $0.30(0.04)$ & $0.31(0.06)$ & $\mathbf{p}=\mathbf{0 . 0 0 1}(0.123)$ & -0.08 to -0 . \\
\hline Max Adduction Moment LP & $0.29(0.10)$ & $0.31(0.10)$ & $0.33(0.12)$ & $0.30(0.10)$ & $0.32(0.08)$ & $0.34(0.09)$ & $\mathrm{p}=0.608(0.003)$ & -0.05 to 0 \\
\hline Coronal Moment Range LP $*$ & $0.15(0.05)$ & $0.14(0.05)$ & $0.13(0.05)$ & $0.18(0.08)$ & $0.19(0.09)$ & $0.19(0.10)$ & $\mathbf{p}=\mathbf{0 . 0 0 6}(0.087)$ & -0.07 to -0 . \\
\hline Transverse Moment Range FC & $0.05(0.03)$ & $0.04(0.03)$ & $0.04(0.02)$ & $0.06(0.03)$ & $0.05(0.02)$ & $0.05(0.02)$ & $\mathbf{p}=\mathbf{0 . 0 0 4}(0.078)$ & -0.024 to -0 . \\
\hline Transverse Moment Range LP & $0.08(0.04)$ & $0.07(0.04)$ & $0.09(0.05)$ & $0.08(0.04)$ & $0.09(0.04)$ & $0.09(0.04)$ & $\mathrm{p}=0.787(0.001)$ & -0.020 to $0 .($ \\
\hline
\end{tabular}

$*$ significant difference between Groups $\uparrow$ significant difference between Orthoses $\$$ significant interaction between Group and Orthoses

(FC - Forward continuum phase, LP - Lowering phase) 
Table 3. Pairwise comparisons for Knee kinematics and Moments during step descent (where a significant main effect was seen for foot orthoses)

\begin{tabular}{|c|c|c|c|c|c|}
\hline \multirow{3}{*}{ Coronal Moment Range FC } & \multicolumn{2}{|c|}{ Comparison between orthoses } & Mean Difference & p-value & CI of the Differences \\
\cline { 2 - 6 } & Shoe & $3 / 4$ & 0.042 & $\mathbf{p}=\mathbf{0 . 0 1 9}$ & 0.007 to 0.077 \\
\cline { 2 - 6 } & Shoe & FL & 0.040 & $\mathbf{p}=\mathbf{0 . 0 2 8}$ & 0.004 to 0.075 \\
\cline { 2 - 6 } & $3 / 4$ & FL & -0.002 & $\mathrm{p}=0.902$ & -0.037 to 0.033 \\
\hline
\end{tabular}

(FC - Forward continuum phase, LP - Lowering phase) 